\title{
Synthesis of new D-A polymers containing disilanobithiophene donor and application to bulk heterojunction polymer solar cells
}

\author{
Makoto Nakashima ${ }^{1}$, Takanori Otsura ${ }^{2}$, Hiroyoshi Naito ${ }^{2}$ and Joji Ohshita ${ }^{1}$ \\ New donor-acceptor-conjugated polymers with disilanobithiophene as the donor and dithienylbenzothiadiazole, \\ thienopyrroledione or diketopyrrolopyrrole as the acceptor were synthesized and their optical and electrochemical properties were \\ investigated. The polymers were black solids and showed broad absorption bands in the visible region. The most red-shifted \\ absorption band having a maximum and an edge of $739 \mathrm{~nm}$ and $1.4 \mathrm{eV}$, respectively, was obtained when diketopyrrolopyrrole \\ was used as the acceptor. The absorption bands were shifted to lower energies when the spectra of the polymers were measured \\ as films, likely due to the interchain interaction of the polymers in the films. Cyclic voltammetry studies of the polymer films \\ were also carried out. The highest occupied molecular orbital (HOMO) and lowest unoccupied molecular orbital (LUMO) energy \\ levels based on the anodic peak onsets and the optical band gaps were -5.1 to -5.5 and -3.5 to $-3.7 \mathrm{eV}$, respectively, \\ depending on the acceptor structures. Bulk heterojunction polymer solar cells that used the present polymers as host material \\ (indium tin oxide (ITO)/poly(3,4-ethylenedioxythiophene) (PEDOT):polystyrene sulfonate (PSS)/disilane-bridged bithiophene- \\ polymer: $\mathrm{PC}_{71} \mathrm{BM} / \mathrm{Ca} / \mathrm{Al}$ ) were fabricated, and a maximal power conversion efficiency of $2.49 \%$ was achieved based on the \\ polymer with bis(hexylthienyl)benzothiadiazole as the acceptor.
}

Polymer Journal (2015) 47, 733-738; doi:10.1038/pj.2015.61; published online 19 August 2015

\section{INTRODUCTION}

Bulk heterojunction polymer solar cells (BHJ-PSCs) have received much attention because of such advantages as low production cost, light weight and mechanical flexibility. The BHJ-PSC possesses an active layer composed of an electron-donating host polymer and an accepting guest compound, such as $\mathrm{PC}_{61} \mathrm{BM}$ and $\mathrm{PC}_{71} \mathrm{BM}$. Recent advances in BHJ-PSCs have been achieved by the use of $\pi$-conjugated polymers bearing alternately arranged donor-acceptor (D-A) units as host materials. ${ }^{1,2}$ The D-A polymers usually show broad absorptions arising from the small band gaps that make it possible to utilize a wide range of sunlight wavelengths, and their polar structures promote photo-induced charge separation. In addition, their electronic states are readily tunable by changing the donor and/or acceptor structures, providing the desired properties. The host polymers should exhibit strong interchain interaction in the solid state, which leads to high hole mobility, thus enhancing the photocurrent. It is also known that the polymers should have low-lying HOMO. The low-lying HOMO elevates open-circuit voltage $\left(V_{\mathrm{oc}}\right)$ that collates the energy gap between the polymer HOMO and PCBM LUMO levels.

Element-bridged 2,2'-bithiophene derivatives have been studied as a donor component of the D-A polymers. ${ }^{3-13}$ In those bridged bithiophene systems, the bithiophene unit is fixed to be highly planar to enhance the $\pi$-conjugation. The nature of the bridging element often affects the bithiophene electronic states significantly. For example, in silicon- and germanium-bridged bithiophenes (DTS and DTG in Scheme 1), the bonding interaction between the silicon or germanium $\sigma^{\star}$ and the bithiophene $\pi^{\star}$-orbital stabilizes LUMO. On the other hand, HOMO is also lowered, albeit slightly, to further minimize the HOMO-LUMO energy gap. ${ }^{14,15}$ In fact, DTS- or DTG-containing D-A type polymers have been prepared and their photovoltaic properties have been demonstrated in BHJ-PSCs. ${ }^{7-13}$ Examples include those containing dithienylbenzothiadiazole (pDTS-BTBT), ${ }^{9}$ thienopyrroledione $(\mathrm{pDTS}-\mathrm{TPD})^{8}$ and diketopyrrolopyrrole (pDTS-DPP) ${ }^{10}$ as the acceptor (see Schemes 1 and 2 for details). Among those cells, higher than 7\% PCE (power conversion efficiency) was achieved by employing pDTS-TPD as the host material. ${ }^{8}$ On the other hand, BHJ-PSCs using some of the DTG-containing D-A polymers exhibited higher performance than those using the DTS-containing analogs. ${ }^{12,13}$

Previously, we found that disilane-bridged bithiophene (DSBT) showed even lower HOMO and LUMO levels than, and a band gap similar to, those of DTS and DTG. ${ }^{16-18}$ Recently, we prepared a DSBT-benzothiadiazole (BT) alternating polymer (pDSBT-BT) in hopes that BHJ cells using the DSBT-containing polymers would

${ }^{1}$ Department of Applied Chemistry, Graduate School of Engineering, Hiroshima University, Higashi-Hiroshima, Japan and ${ }^{2}$ Department of Physics and Electronics, Graduate School of Engineering, Osaka Prefecture University, Osaka, Japan

Correspondence: Professor H Naito, Department of Physics and Electronics, Graduate School of Engineering, Osaka Prefecture University, 1-1 Gakuen-cho, Naka-ku, Osaka 5998531, Japan.

E-mail: naito@pe.osakafu-u.ac.jp

or Professor J Ohshita, Department of Applied Chemistry, Graduate School of Engineering, Hiroshima University, 1-4-1 Kagamiyama, Higashi-Hiroshima 739-8527, Japan. E-mail: jo@hiroshima-u.ac.jp

Received 1 May 2015; revised 14 July 2015; accepted 17 July 2015; published online 19 August 2015 
<smiles>[R][R]1([R])c2ccsc2c2sccc21</smiles><smiles>[R][R]1c2ccsc2c2scc[R9]:12[R]</smiles>

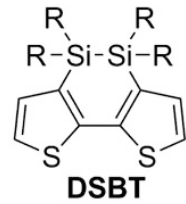<smiles>[R][R]1([R])c2cnsc2c2sc(CC)cc21</smiles>
(n) pDTS-BT

$R=$ 2-ethylhexyl

Scheme 1 Structures of silicon- (DTS), germanium-bridged bithiophenes (DTG) and disilane-bridged bithiophene (DSBT), and their polymers.

show high performance arising from a high $V_{\text {oc }}$. Indeed, PCE reached $6.38 \%$, which is higher than that reported for a similar cell using pDTS-BT, as expected (Scheme 1)., ${ }^{719}$

To explore further the scope of DSBT-containing D-A polymers as BHJ-PSC materials, we prepared new DSBT polymers containing dithienylbenzothiadiazole, thienopyrroledione or diketopyrrolopyrrole as the acceptor. We examined them with respect to the optical and electrochemical properties to know their electronic states, and carried out preliminary work to apply them to BHJ-PSC.

\section{EXPERIMENTAL PROCEDURE}

\section{General}

All reactions were carried out under a dry argon atmosphere. THF, ether and toluene used as reaction solvents were distilled from calcium hydride and were stored over activated molecular sieves before use. Monomers 4,4,5,5-tetrabutyl2,7-bis(trimethylstannyl)dithieno[3,2-c:2',3'-e] disilacyclohexadiene (DSBTSn), ${ }^{19}$ 4,7-bis(5-bromo-2-thienyl)-2,1,3-benzothiadiazole (BTBT), ${ }^{20}$ 4,7-bis(4-hexyl5-iodo-2-thienyl)-2,1,3-benzothiadiazole (BHTBT), ${ }^{21}$ 1,3-dibromo-5-octyl-4Hthieno[3,4-c]pyrrole-4,6(5H)-dione (TPD) ${ }^{22}$ and 3,6-bis(5-bromo-2-thienyl)2,5-bis(2-ethylhexyl)pyrrolo[3,4-c]pyrrole-1,4-dione (DPP) ${ }^{10}$ were prepared according to literature procedure. Other materials were commercially available and used as obtained. Nuclear magnetic resonance (NMR) spectra were measured on Varian 400-MR and Varian System 500 spectrometers (Agilent Inc., Santa Clara, CA, USA). Ultraviolet-visible (UV-vis) absorption spectra were measured on a Shimadzu-UV-3150 spectrometer (Shimadzu Co., Kyoto, Japan). Gel permeation chromatography (GPC) was carried out using serially connected Shodex KF2001 and KF2002 columns (Showa Denko K.K., Tokyo, Japan) and THF as the eluent. Using the present polymers, BHJ-PSC devices $^{23}$ were fabricated as reported in the literature, except that $\mathrm{Ca} / \mathrm{Al}$ was used as the cathode material instead of LiF/Al.

\section{Preparation of DSBT-containing polymers}

A mixture of $200 \mathrm{mg}(0.258 \mathrm{mmol})$ of DSBTSn, $118 \mathrm{mg}(0.258 \mathrm{mmol})$ of BTBT, $11.8 \mathrm{mg}\left(1.29 \times 10^{-2} \mathrm{mmol}\right)$ of $\mathrm{Pd}_{2}(\mathrm{dba})_{3}, 15.9 \mathrm{mg}\left(5.16 \times 10^{-2} \mathrm{mmol}\right)$ of (o-tolyl $)_{3} \mathrm{P}$ and $15 \mathrm{ml}$ of toluene was stirred at $70^{\circ} \mathrm{C}$ for 3 days. The mixture was allowed to cool to room temperature and the resulting precipitates were filtered. The precipitates were placed in a Soxhlet apparatus and extracted with hot toluene. The filtrate and the extract were combined. The solvent was removed in vacuo and the residue was dissolved in o-dichlorobenzene. The palladium species in the mixture was removed by adding $30 \mathrm{ml}$ of an aqueous solution of sodium $\mathrm{N}, \mathrm{N}$-diethyldithiocarbamate trihydrate $(10 \%)$ and then heating the mixture to $85^{\circ} \mathrm{C}$ for $2 \mathrm{~h}$. The organic layer was separated and washed with water, 3 vol\% acetic acid aqueous solution and water again. The organic layer was separated and dried over anhydrous magnesium sulfate. After the solvent was removed by evaporation, the residue was subjected to reprecipitation from $o$-dichlorobenzene/methanol and then $o$-dichlorobenzene/ethanol to provide $12.0 \mathrm{mg}$ ( $6 \%$ yield) of pDSBT-BTBT as

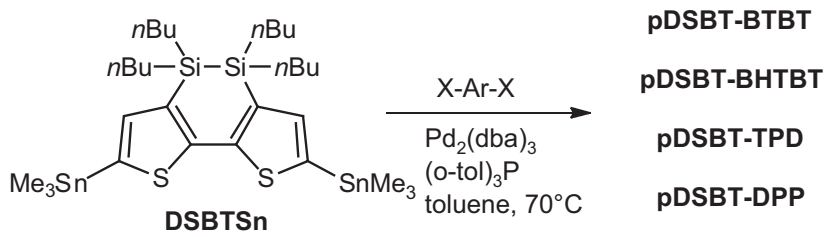

X-Ar-X=
BHTBT $(\mathrm{R}=\mathrm{H}, \mathrm{X}=\mathrm{Br})$
BHex, $\mathrm{X}=\mathrm{I})$<smiles>[R]N1C(=O)c2c(Br)sc(Br)c2C1=O</smiles><smiles>[R]N1C(=O)c2c(-c3ccc(Br)s3)n([R])c(=[R]#P)c2=C1c1ccc(Br)s1</smiles>

Scheme 2 Synthesis of D-A polymers.

a dark purple solid: melting point $(\mathrm{mp})>300{ }^{\circ} \mathrm{C} ;{ }^{1} \mathrm{H}$ NMR (in $\mathrm{C}_{6} \mathrm{D}_{5} \mathrm{Cl}$ ) $\delta$ : 0.91-1.54 (br m, 36H, Bu), 7.23-7.28 (br m, 2H, thiophene), 7.57-7.60 (br m, $4 \mathrm{H}$, thiophene), 8.05 (br s, $2 \mathrm{H}, \mathrm{BT}$ ). No signals could be observed in the ${ }^{13} \mathrm{C}$ NMR spectrum because of the low solubility. GPC $M_{\mathrm{n}}=19000, M_{\mathrm{w}}=23000$, $M_{\mathrm{w}} / M_{\mathrm{n}}=1.2$; UV-vis abs $\lambda_{\max }=574 \mathrm{~nm}$ (in $o-\mathrm{C}_{6} \mathrm{H}_{4} \mathrm{Cl}_{2}$ ).

Other DSBT-containing polymers were obtained in a manner similar to that above. Data for pDSBT-BHTBT are as follows: dark purple solid; $54 \%$ yield after reprecipitation from chlorobenzene/ethanol and then chlorobenzene/ethyl acetate; $\mathrm{mp}>300{ }^{\circ} \mathrm{C} ;{ }^{1} \mathrm{H}$ NMR (in $o-\mathrm{C}_{6} \mathrm{D}_{4} \mathrm{Cl}_{2}$ ) $\delta: 0.87-1.82(\mathrm{~m}, 58 \mathrm{H}, \mathrm{Bu} \mathrm{Hex}$ ), 2.97 (br s, 4H, Hex), 7.54 (br s, $2 \mathrm{H}$, thiophene), 7.77 (br s, $2 \mathrm{H}$, thiophene), 8.16 (br s, $2 \mathrm{H}, \mathrm{BT}$ ); ${ }^{13} \mathrm{C}$ NMR (in $o-\mathrm{C}_{6} \mathrm{D}_{4} \mathrm{Cl}_{2}$ ) $\delta: 12.86,13.88,14.36,23.03$, 26.91, 27.43, 29.74, 30.21, 30.84, 32.03, 125.02, 125.36, 131.21, 134.75, 135.11, $137.18,140.85,145.45,152.53 ;$ GPC $M_{\mathrm{n}}=7800, M_{\mathrm{w}}=12800, M_{\mathrm{w}} / M_{\mathrm{n}}=1.6$; UV-vis abs $\lambda_{\max }=572 \mathrm{~nm}$ (in $\mathrm{C}_{6} \mathrm{H}_{5} \mathrm{Cl}$ ). Data for pDSBT-TPD are as follows: red-purple solid; $55 \%$ yield after reprecipitation from toluene/ethanol and then toluene/2-propanol; $\mathrm{mp}>300{ }^{\circ} \mathrm{C} ;{ }^{1} \mathrm{H} \mathrm{NMR}$ (in $\mathrm{C}_{6} \mathrm{D}_{6}$ ) $\delta: 0.90-1.67$ (br m, $51 \mathrm{H}$, $\mathrm{Bu}$, octyl), 3.62 (br s $2 \mathrm{H}$, octyl), 8.79 (br s, $2 \mathrm{H}$, thiophene); ${ }^{13} \mathrm{C} \mathrm{NMR}$ (in $\mathrm{C}_{6} \mathrm{D}_{6}$ ) $\delta: 13.06,14.07,14.40,23.09,27.13,27.38,27.63,29.03,29.61,32.23$ ( $\mathrm{sp}^{2}$ carbon signals could not be seen because of low polymer solubility): GPC $M_{\mathrm{n}}=7600$, $M_{\mathrm{w}}=10000, M_{\mathrm{w}} / M_{\mathrm{n}}=1.3$; UV-vis abs $\lambda_{\max }=516 \mathrm{~nm}$ (in THF). Data for pDSBT-DPP are as follows: black solid; $73 \%$ yield, after reprecipitation from chlorobenzene/ethanol and then chlorobenzene/ethyl acetate; $\mathrm{mp}>300{ }^{\circ} \mathrm{C} ;{ }^{1} \mathrm{H}$ NMR (in $o-\mathrm{C}_{6} \mathrm{D}_{4} \mathrm{Cl}_{2}$ ) $\delta: 0.92-2.06$ (br m, 66 H Bu 2-ethylhexyl), 4.09 (br m, $4 \mathrm{H}$ ), 7.47-7.53 (br m, 4H, thiophene of DSBT and DPP), 9.31 (br s, $2 \mathrm{H}$, thiophene of $\mathrm{DPP}$ ); ${ }^{13} \mathrm{C}$ NMR (in $o-\mathrm{C}_{6} \mathrm{D}_{4} \mathrm{Cl}_{2}$ ) $\delta: 10.50,12.74,13.84$, $14.43,23.48,23.83,26.88,27.35,28.88,30.12\left(\mathrm{sp}^{2}\right.$ carbon signals could not be seen because of low polymer solubility): GPC $M_{\mathrm{n}}=87700, M_{\mathrm{w}}=380000$, $M_{\mathrm{w}} / M_{\mathrm{n}}=4.3$; UV-vis abs $\lambda_{\max }=739 \mathrm{~nm}$ (in $\mathrm{C}_{6} \mathrm{H}_{5} \mathrm{Cl}$ ).

\section{RESULTS AND DISCUSSION}

\section{Polymer synthesis}

D-A polymers bearing DSBT donor units were prepared by the palladium-catalyzed Stille coupling reactions of DSBTSn with acceptor monomers BTBT, BHTBT, TPD and DPP, under the same conditions as those for preparing pDSBT-BT reported previously (Scheme 2). ${ }^{19}$ The reaction progress was monitored by GPC. All the reactions were completed within 3 days and no monomers remained in the reaction mixture, except the reaction with BHTBT that required heating for 5 days. The polymers were obtained as dark purple or black solids. 
The solubility of the present polymers was dependent on the acceptor structures. pDSBT-BTBT that contains no alkyl side chains on the acceptor unit showed low solubility. Indeed, the polymerization for pDSBT-BTBT provided a large amount of insoluble substances that were separated by filtration, being responsible for the low yield $(6 \%)$. It was slightly soluble in $o$-dichlorobenzene, barely soluble in chlorobenzene, and nearly insoluble in chloroform, toluene, acetone, hexane, ethyl acetate and ethanol at room temperature. Polymers pDSBT-BHTBT and -DPP having alkyl groups on the acceptor units showed higher solubilities; they were highly soluble in $o$-dichlorobenzene, moderately soluble in chlorobenzene and slightly soluble in toluene and chloroform. However, they were still insoluble in acetone, hexane, ethyl acetate and ethanol. pDSBT-TPD showed even higher solubility; it was soluble in common organic solvents, such as acetone, ethyl acetate, hexane, THF, toluene, chlorobenzene and $o$-dichlorobenzene, but not in ethanol. Because of the low solubility, GPC of pDSBT-BTBT was carried out at $140{ }^{\circ} \mathrm{C}$ using chlorobenzene as the eluent, whereas other polymers were readily eluted at ambient temperature using THF as the eluent. Polymer pDSBT-BTBT had a higher molecular weight than pDSBT-BHTBT. It is likely that the sterically large $n \mathrm{Hex}$ groups on the thiophene unit suppressed the polymerization. Polymer pDSBT-DPP showed the highest molecular weight among the present polymers. The reason for the low molecular weight of pDSBT-TPD is unclear. However, it is speculated that the carbonyl units also hinder the coupling reactions.

The polymer structures were verified by ${ }^{1} \mathrm{H}$ and ${ }^{13} \mathrm{C} N M R$ measurements (see Supplementary Information for ${ }^{1} \mathrm{H}$ NMR spectra of the present polymers). The aromatic region in the ${ }^{1} \mathrm{H}$ NMR spectrum of pDSBT-BHTBT is depicted in Figure 1 as a typical example. Three singlets ascribed to thiophene and benzene protons, together with small signals that may be due to the influence of the end groups, were observed. The thermal stability of the present polymers was confirmed by thermogravimetric analysis, which showed 5\% weight loss at temperatures higher than $400^{\circ} \mathrm{C}$ in nitrogen (Table 1).

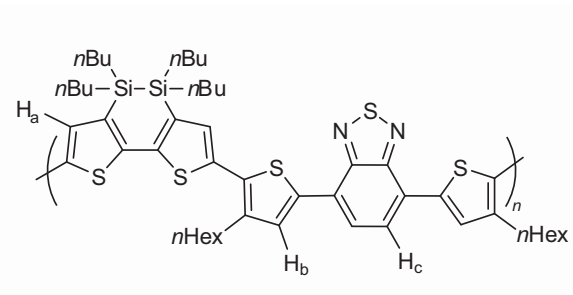

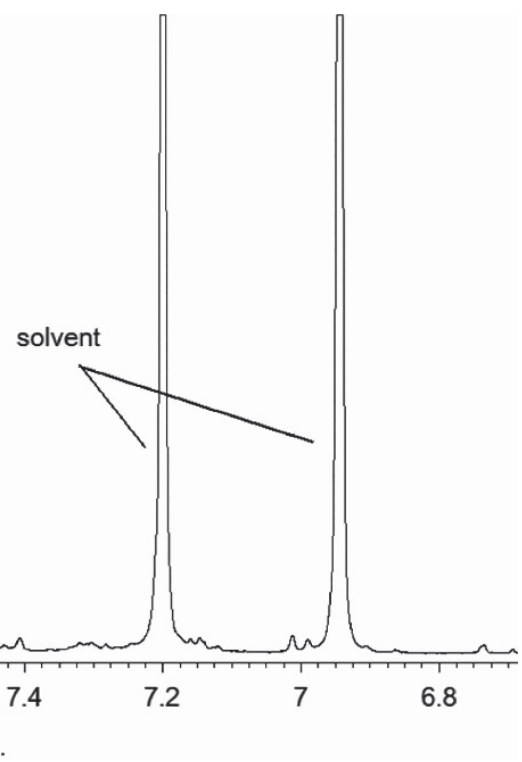

Figure 1 Aromatic region in ${ }^{1} \mathrm{H}$ NMR spectrum of pDSBT-BHTBT in ${ }^{-}-\mathrm{C}_{6} \mathrm{D}_{4} \mathrm{Cl}_{2}$.

Table 1 Polymer properties

\begin{tabular}{|c|c|c|c|c|c|c|c|c|c|c|}
\hline \multirow[t]{2}{*}{ Polymer } & \multirow[t]{2}{*}{ Yield (\%) } & \multirow[t]{2}{*}{ m.p. $\left({ }^{\circ} \mathrm{C}\right)$} & \multirow[t]{2}{*}{$\mathrm{M}_{n}\left(\mathrm{gmol}^{-1}\right)^{\mathrm{a}}$} & \multirow[t]{2}{*}{$\mathrm{M}_{w} \mathrm{M}_{n}^{\mathrm{a}}$} & \multirow[t]{2}{*}{$\mathrm{T}_{d}{ }^{5 \mathrm{~b}}\left({ }^{\circ} \mathrm{C}\right)$} & \multicolumn{2}{|c|}{$\begin{array}{l}\text { UV-vis abs } \lambda_{\max } \\
(n m)\end{array}$} & \multirow[t]{2}{*}{$\mathrm{E}_{g}(\mathrm{eV})^{\mathrm{c}}$} & \multirow[t]{2}{*}{$\mathrm{E}_{\text {HOMO }}(\mathrm{eV})^{\mathrm{d}}$} & \multirow[t]{2}{*}{$E_{\text {LUMO }}(\mathrm{eV})^{\mathrm{e}}$} \\
\hline & & & & & & Solution & Film & & & \\
\hline pDSBT-BTBT & 6 & $-^{f}$ & 19000 & 1.2 & ND & $574^{g}$ & 615 & 1.8 & ND & ND \\
\hline pDSBT-BHTBT & 54 & $-^{f}$ & 7800 & 1.6 & 431 & $584^{h}$ & 635 & 1.7 & -5.2 & -3.5 \\
\hline pDSBT-TPD & 55 & $-^{f}$ & 7600 & 1.3 & 429 & $516^{j}$ & 537 & 1.9 & -5.5 & -3.6 \\
\hline pDSBT-DPP & 73 & $-^{f}$ & 87700 & 4.3 & 412 & $739^{h}$ & 747 & 1.4 & -5.1 & -3.7 \\
\hline pDSBT-BT ${ }^{\mathrm{i}}$ & 49 & $-^{f}$ & 20000 & 1.9 & 447 & $633^{j}$ & 689 & 1.7 & -5.2 & -3.5 \\
\hline
\end{tabular}

Abbreviations: BHTBT, 4,7-bis(4-hexyl-5-iodo-2-thienyl)-2,1,3-benzothiadiazole; BTBT, 4,7-bis(5-bromo-2-thienyl)-2,1,3-benzothiadiazole; DPP; 3,6-bis(5-bromo-2-thienyl)-2,5-bis(2-ethylhexyl) pyrrolo[3,4-c]pyrrole-1,4-dione; ND, not determined; TPD, 1,3-dibromo-5-octyl-4H- thieno[3,4-c]pyrrole-4,6(5H)-dione; UV-vis, ultraviolet-visible.

a Determined by gel permeation chromatography relative to polystyrene standards.

${ }^{b}$ By thermogravimetric analysis in nitrogen at $10^{\circ} \mathrm{C} \mathrm{min}^{-1}$.

'Based on UV absorption edge of polymer solution.

Based on cyclic voltammograms oxidation peak onset of polymer cast film.

EEstimated from the HOMO energy level and optical band gap.

${ }^{\mathrm{f}}>300^{\circ} \mathrm{C}$.

gIn o-dichlorobenzene.

hIn chlorobenzene.

isee reference ${ }^{19}$

IIn THF. 
Optical and electrochemical properties

The optical properties of the present polymers in solution and as films were examined with respect to their UV-vis spectra (Figure 2). All the polymers in solution showed broad absorption bands in the UV-vis
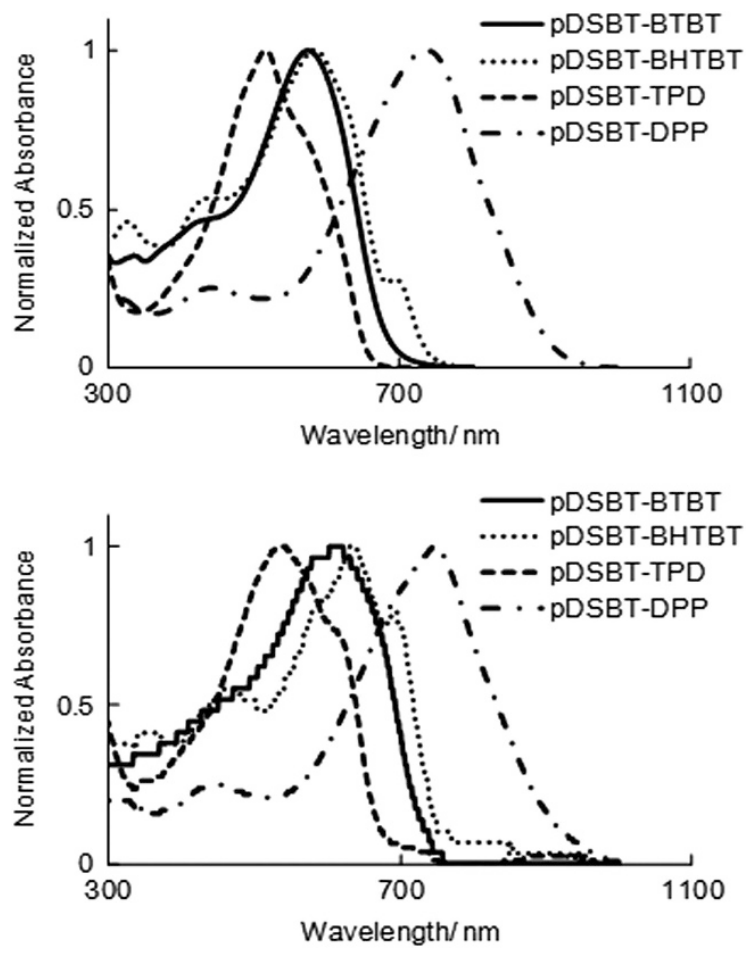

Figure 2 Ultraviolet-visible absorption spectra of disilane-bridged bithiophene (DSBT) polymers in solution (pDSBT-BTBT in o-dichlorobenzene, pDSBT-BHTBT in chlorobenzene, pDSBT-TPD in tetrahydrofuran and pDSBT-DPP in chlorobenzene; top) and as films (bottom). BHTBT, 4,7-bis(4-hexyl-2-thienyl)-2,1,3-benzothiadiazole; BTBT, 4,7-bis(2-thienyl)2,1,3-benzothiadiazole; DPP; 3,6-bis(2-thienyl)-2,5-bis(2-ethylhexyl)pyrrolo [3,4-c]pyrrole-1,4-dione; TPD, 5-octyl-4H-thieno[3,4-c]pyrrole-4,6(5H)-dione. region, which were red-shifted when the polymers were measured as films. The UV-vis spectra of polymers pDSBT-BHTBT and -TPD, both of which possessed relatively low molecular weights, showed shoulders in the low energy region in solution, and the shoulder peaks were enhanced when they were measured as films. This tendency was similar to that reported for $\mathrm{pDSBT}^{\mathrm{B} T}{ }^{19}$ indicating that interchain $\pi-\pi$ interaction was enhanced in films. A similar enhancement of a lower energy band of the conjugated polymers by the formation of aggregates has been well established. ${ }^{24-27}$ On the other hand, polymers pDSBT-BTBT and -DPP having relatively high molecular weights showed similar UV-vis spectra regardless of the condition, that is, in solution or as films, although some redshifts of the absorptions were observed when they were measured as films. This seems to suggest that those polymers possess sufficient $\pi-\pi$ interaction even in solution. The UV absorption maxima of the polymers were shifted to lower energies in the order of pDSBT-TPD $<-$ BTBT and -BHTBT <-BT <-DPP. Polymer pDSBT-DPP showed the most red-shifted absorption maximum with its absorption edge reaching $910 \mathrm{~nm}$. This tendency is consistent with that of the DTS analogs (Scheme 3), except pDTS-TPD ${ }^{8}$ that shows a red-shifted absorption band relative to that of pDTS-BTBT. ${ }^{11}$ This may be due to the low molecular weight of pDSBT-TPD, which moves the band to higher energy. When the $\lambda_{\max }$ values were compared with those reported for the DTS analogs shown in Scheme 3, the present DSBT polymers showed absorption maxima at higher energies, except pDSBT-BTBT whose maxima appeared at approximately 10 and $20 \mathrm{~nm}$ lower energies than those of pDTS-BTBT in solution and as film, respectively. The blue-shifted absorptions are likely due to the twisted bithiophene structure in DSBT. This tendency is similar to the finding that the maxima of PDSBT-BT appear at higher energies than those of pDTS-BT in solution and as film. ${ }^{19}$

The cyclic voltammograms of the polymer cast films containing lithium perchlorate as the supporting electrolyte on platinum electrodes were measured in acetonitrile (Figure 3). The cyclic voltammograms showed irreversible profiles. The HOMO energy levels of the polymers were estimated from the onset oxidation potentials, which were similar to that of pDSBT-BT (Table 1), except

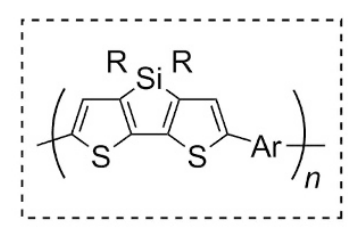<smiles>[R]c1cc(C2=CC=C(c3cc([R])c(C)s3)C(=NS)C2=N)sc1C</smiles>

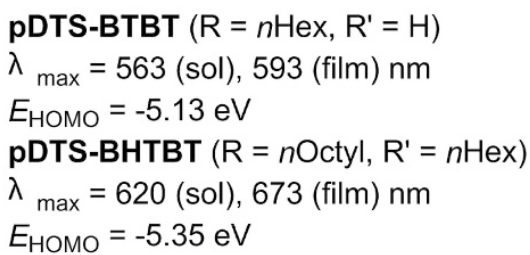<smiles>[R]N1C(=O)c2c(C)sc(C)c2C1=O</smiles><smiles>[R]N1C(=O)C2=C(c3ccc(C)s3)N([R])C(=O)C2=C1c1ccc(C)s1</smiles>

pDTS-TPD (R = 2-ethylhexyl, R' = nOctyl)

$\lambda_{\text {max }}=670$ (sol), 670 (film) nm

$E_{\mathrm{HOMO}}=-5.57 \mathrm{eV}$

pDTS-DPP (R = R' = 2-ethylhexyl)

$\lambda_{\text {max }}=798$ (sol), 796 (film) $\mathrm{nm}$

$E_{\mathrm{HOMO}}=-5.04 \mathrm{eV}$

Scheme 3 Structures of silicon-bridged bithiophene (DTS) polymers. ${ }^{8-11}$ 
for pDSBT-TPD that revealed an onset at a high voltage. These data were comparable to those reported for the DTS analogs (Scheme 3). However, it was noted that pDSBT-BTBT and pDSBT-DPP possessed slightly lower-lying HOMO than the DTS analogs, and are thus expected as high $V_{\mathrm{oc}}$ materials, similar to pDSBT-BT.

\section{Applications to $\mathrm{BHJ}-\mathrm{PSC}$}

$\mathrm{BHJ}$-PSCs using the present D-A polymers as host materials were fabricated with the structure of ITO/PEDOT:PSS/DSBT-polymer: $\mathrm{PC}_{71} \mathrm{BM} / \mathrm{Ca} / \mathrm{Al}$ and the active area of $0.25 \mathrm{~cm}^{2}$. The active layers were prepared by spin coating chlorobenzene solutions of the blends of the polymers and $\mathrm{PC}_{71} \mathrm{BM}$ in the weight ratio of 1:1.5 containing $2.5 \mathrm{vol} \%$ diiodooctane as processing additive. The device structures are nearly the same as that of our previous work. ${ }^{19}$ In the present work, however, we used $\mathrm{Ca} / \mathrm{Al}$ as the cathode instead of $\mathrm{LiF} / \mathrm{Al}$, expecting that the lower work function of $\mathrm{Ca} / \mathrm{Al}$ would improve the performance. The device based on pDSBT-BT was also reinvestigated using a Ca electrode. For each of the polymers, 24 cells were prepared and examined showing similar properties depending on the polymers. The $J-V$ curves and the incident photon to current conversion efficiency (IPCE) spectra of the cells that provided the best performance for each polymers are shown in Figure 4 . All the cells exhibited clear photovoltaic activities except the pDSBT-TPD-based one that showed markedly inferior performance to the others, likely due to the low molecular weight that would suppress film quality then carrier transport in the film. To know about the film morphology, AFM of a pDSBT-TPD film was examined, indicating high surface roughness with an average roughness $\left(R_{\mathrm{a}}\right)$ and a maximum height difference $\left(R_{\max }\right)$ of 1.05 and $5.98 \mathrm{~nm}$, respectively. These values were much higher than those of pDSBT-BHTBT $\left(R_{\mathrm{a}}=0.197 \mathrm{~nm}, R_{\max }=1.03 \mathrm{~nm}\right)$ that exhibited much better photovoltaic properties in the cell. Although surface roughness does not directly collate the cell performance, the difference in surface roughness seems to reflect the different aggregation behavior of the polymers, which is an important factor affecting the polymer carrier mobility. The device with pDSBT-BHTBT showed the highest energy conversion efficiency among the presently investigated ones. Its IPCE showed a maximum of $\sim 60 \%$ in the wavelength range of $500-600 \mathrm{~nm}$

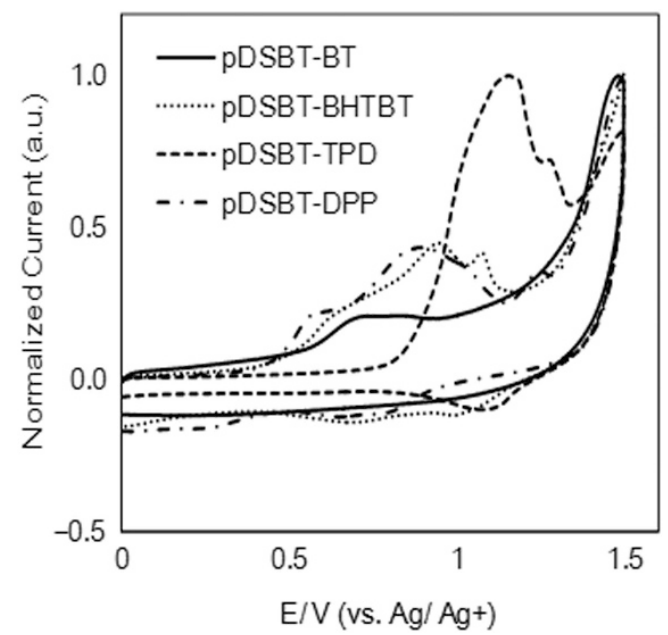

Figure 3 Cyclic voltammograms of polymer cast films. BHTBT, 4,7-bis(4hexyl-5-iodo-2-thienyl)-2,1,3-benzothiadiazole; BT, benzothiadiazole; DPP; 3,6-bis(5-bromo-2-thienyl)-2,5-bis(2-ethylhexyl)pyrrolo[3,4-c]pyrrole-1,4dione; TPD, 1,3-dibromo-5-octyl-4H-thieno[3,4-c]pyrrole-4,6(5H)-dione.
(Figure 4), compared with only $30 \%$ or $10 \%$ IPCE obtained for the other devices in the same wavelength range. The IPCE spectrum of pDSBT-DPP showed the most red-shifted edge, in agreement with its UV-vis absorption spectrum.

The cell parameters are summarized in Table 2. The cell with pDSBT-BHTBT showed the highest PCE among the present cells. Although the PCE was lower than that of the cell based on pDSBT-BT with a $\mathrm{Ca} / \mathrm{Al}$ cathode, higher $V_{\mathrm{oc}}$ and $J_{\mathrm{sc}}$ were provided by the pDSBT-BHTBT-based cell. The lower PCE was thus due to its low fill factor (FF) as compared with the cell with pDSBT-BT, which would arise from high series resistance $\left(R_{\mathrm{S}}\right)$. It was noted that FF of the cell with pDSBT-BHTBT is lower also than those with pDSBT-BT and pDSBT-DPP. In addition, the $J-V$ curve of the pDSBT-BHTBT-based cell showed inferior rectification properties. The FF value, however, may be improved by optimization of cell fabrication parameters, such as layer thickness, polymer/PC $\mathrm{P}_{71} \mathrm{BM}$ ratio, spin-coating solvent and so on. Unfortunately, changing the cathode material from $\mathrm{LiF} / \mathrm{Al}$ to $\mathrm{Ca} / \mathrm{Al}$ did not improve the performance of the cell based on pDSBT-BT.

\section{CONCLUSIONS}

In summary, we prepared new D-A type polymers with DSBT as the donor unit and investigated their optical and electrochemical properties, indicating that some of the present polymers possess slightly lower-lying HOMO than those of the DTS analogs, in accordance to our expectation, being potentially useful as highvoltage PSC materials, like pDSBT-BT. The polymers indeed showed photovoltaic activities in BHJ-PSCs. Of those, pDSBT-BHTBT showed
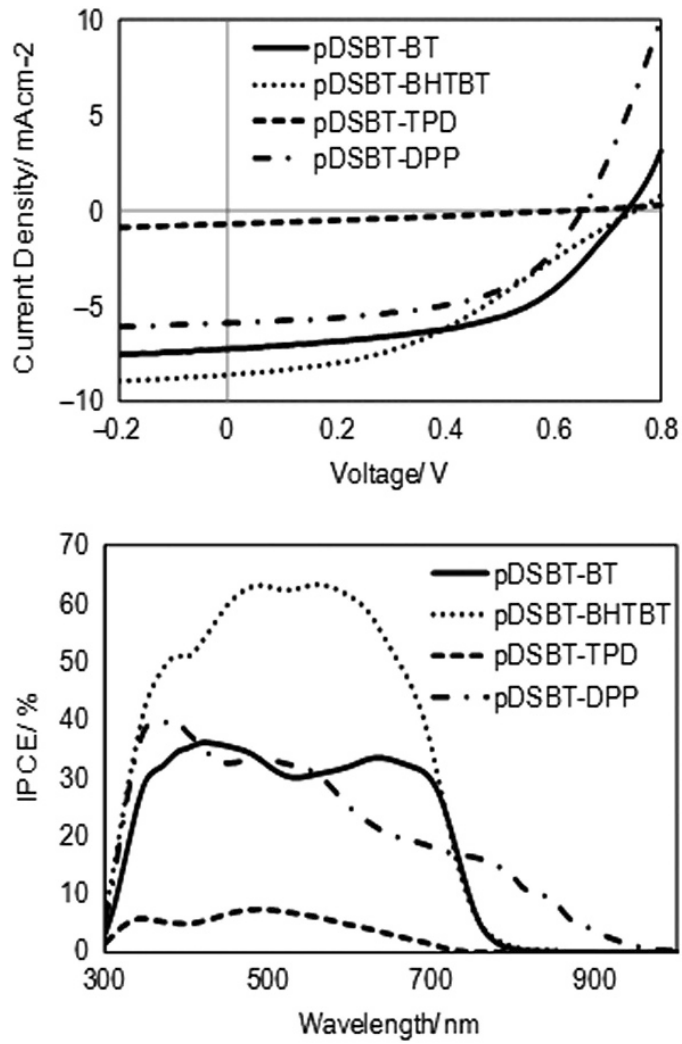

Figure $4 \mathrm{~J}$-V curves (top) and IPCE spectra of bulk heterojunction polymer solar cells based on disilane-bridged bithiophene polymers (bottom). BHTBT, 4,7-bis(4-hexyl-2-thienyl)-2,1,3-benzothiadiazole; BT, benzothiadiazole; DPP; 3,6-bis(2-thienyl)-2,5-bis(2-ethylhexyl)pyrrolo[3,4-c]pyrrole-1,4-dione; TPD, 5octyl-4H-thieno[3,4-c]pyrrole-4,6(5H)-dione. 
Table 2 Photovoltaic properties of D-A polymers

\begin{tabular}{lcccc}
\hline Polymer & $\mathrm{V}_{o c}(V)$ & $\mathrm{J}_{S c}\left(\left(m A c m^{-2}\right)\right.$ & $F F(\%)$ & $P C E(\%)$ \\
\hline pDSBT-BHTBT & 0.76 & 8.64 & 38 & 2.49 \\
pDSBT-TPD & 0.67 & 0.74 & 28 & 0.14 \\
pDSBT-DPP & 0.66 & 5.91 & 54 & 2.13 \\
pDSBT-BT & $0.82^{\mathrm{a}}$ & $12.69^{\mathrm{a}}$ & $60^{\mathrm{a}}$ & $6.38^{\mathrm{a}}$ \\
pDSBT-BT & 0.74 & 7.30 & 53 & 2.84 \\
\hline
\end{tabular}

Abbreviations: BHTBT, 4,7-bis(4-hexyl-5-iodo-2-thienyl)-2,1,3-benzothiadiazole; BT, benzothiadiazole; DPP; 3,6-bis(5-bromo-2-thienyl)-2,5-bis(2-ethylhexyl)pyrrolo[3,4-c]pyrrole-1,4 dione; PCE, power conversion efficiency; TPD, 1,3-dibromo-5-octyl-4H-thieno[3,4-c]pyrrole-4,6 (5H)-dione.

aLiF/Al was used as cathode. ${ }^{19}$

the best performance. The cell based on this polymer provided higher $V_{\mathrm{oc}}$ and $J_{\mathrm{sc}}$ than those of pDSBT-BT, indicative of the high potential. However, FF of the pDTBT-BHTBT-based cell was much lower than that of pDSBT-BT, being responsible for the lower PCE. Studies to improve the performance by optimizing cell structures and fabrication conditions as well as by tuning the polymer molecular structure are under way.

\section{CONFLICT OF INTEREST}

The authors declare no conflict of interest.

\section{ACKNOWLEDGEMENTS}

This work was supported by a Grant-in-Aid for Scientific Research on Innovative Areas 'New Polymeric Materials Based on Element-Blocks (No.2401)' and that for Scientific Research (B) (No. 26288094) from the Ministry of Education, Culture, Sports, Science and Technology, Japan. We thank also Associate Professor Shin-ichi Kihara of Hiroshima University for assistance in GPC measurement at high temperature.

1 Dou, L., Jingbi, J., Hong, Z., Xu, Z., Li, G., Street, A. R. \& Yang, Y. 25th Anniversary article: a decade of organic/polymeric photovoltaic research. Adv. Mater. 25, 6642-6671 (2013).

2 Li, Y.-F. Molecular design of photovoltaic materials for polymer solar cells: toward suitable electronic energy levels and broad absorption. Acc. Chem. Res. 45 723-733 (2012).

3 Albrecht, S., Janietz, S., Schindler, W., Frisch, J., Kurpiers, J., Kniepert, J., Inal, S., Pingel, P., Fostiropoulos, K., Koch, N. \& Neher, D. Fluorinated copolymer PCPDTBT with enhanced open-circuit voltage and reduced recombination for highly efficient polymer solar cells. J. Am. Chem. Soc. 134, 14932-14944 (2012).

4 Azoulay, D. J., Koretz, A. Z., Wong, M. B. \& Bazan, C. G. Bridgehead imine substituted cyclopentadithiophene derivatives: an effective strategy for band gap control in donor-acceptor polymers. Macromolecules 46, 1337-1342 (2013).

5 Rasmussen, C. S. \& Evenson, J. S. Dithieno[3,2-b:2',3'-d]pyrrole-based materials: synthesis and application to organic electronics. Prog. Polym. Sci. 38 1773-1804 (2013).

6 Yue, W., Zhao, Y., Shao, S., Tian, H., Xie, Z., Geng, Y. \& Wang, F. Novel NIR-absorbing conjugated polymers for efficient polymer solar cells: effect of alkyl chain length on device performance. J. Mater. Chem. 19, 2199-2206 (2009).

7 Hou, J., Chen, H.-Y., Zhang, S., Li, G. \& Yang, Y. Synthesis, characterization, and photovoltaic properties of a low band gap polymer based on silole-containing polythiophenes and 2,1,3-benzothiadiazole. J. Am. Chem. Soc. 130 16144-16145 (2008).

8 Chu, T.-Y., Lu, J., Beaupré, S., Zhang Y., Pouliot, J-R., Zhou, J., Najari, A., Leclerc, M. \& Tao, Y. Effects of the molecular weight and the side-chain length on the photovoltaic performance of dithienosilole/thienopyrrolodione copolymers. Adv. Funct. Mater. 22 2345-2351 (2012).

9 Medlej, H., Awada, H., Abbas, M., Wantz, G., Bousquet, A., Grelet, E., Hariri, K. Hamieh, T., Hiorns, C. R. \& Dagron-Lartigau, C. Effect of spacer insertion in a commonly used dithienosilole/benzothiadiazole-based low band gap copolymer for polymer solar cells. Eur. Polym. J. 49, 4176-4188 (2013).

10 Huo, L., Hou, J., Chen, H.-Y., Zhang, S., Jiang, Y., Chen, L. T. \& Yang, Y. Bandgap and molecular level control of the low-bandgap polymers based on 3,6-dithiophen-2-yl-2, 5-dihydropyrrolo[3,4-c]pyrrole-1,4-dione toward highly efficient polymer solar cells. Macromolecules 42, 6564-6571 (2009).

11 Liao, L., Dai, L., Smith, A., Durstock, M., Lu, J., Ding, J. \& Tao, Y. Photovoltaic-active dithienosilole-containing polymers. Macromolecules 40, 9406-9412 (2007).

12 Small, E. C., Chen, S., Subbiah, J., Amb, M. C., Tsang, S.-W., Lai, T.-H., Reynolds, R. J. \& So, F. High-efficiency inverted dithienogermole-thienopyrrolodione-based polymer solar cells. Nat. Photonics 6, 115-120 (2012)

13 Ohshita, J., Hwang, Y.-M., Mizumo, T., Yoshida, H., Ooyama, Y., Harima, Y. \& Kunugi, $Y$. Synthesis of dithienogermole-containing $\pi$-conjugated polymers and applications to photovoltaic cells. Organometallics 12, 3233-3236 (2011).

14 Ohshita, J. Conjugated oligomers and polymers containing dithienosilole units. Macromol. Chem. Phys. 210, 1360-1370 (2009).

15 Yamaguchi, S., Itami, Y. \& Tamao, K. Group 14 metalloles with thienyl groups on 2,5-positions: effects of group 14 elements on their $\pi$-electronic structures. Organometallics 17, 4910-4916 (1998).

16 Ohshita, J., Nodono, M., Kai, H., Watanabe, T., Kunai, A., Komaguchi, K., Shiotani, M. Adachi, A., Okita, K., Harima, Y., Yamashita, K. \& Ishikawa, M. Synthesis and optical, electrochemical, and electron-transporting properties of silicon-bridged bithiophenes. Organometallics 18, 1453-1459 (1999).

17 Kwak, Y.-W., Lee, I.-S., Baek, M.-K., Lee, U., Choi, H.-J., Ishikawa, M., Naka, A. Ohshita, J., Lee, H.-K. \& Kunai, A. Palladium-catalyzed reactions of 4,4,5,5Tetramethyl-2,7- bis(trimethylsilyl)dithieno[3,2-c:2‘,3'-e]disilacyclohexadiene with alkynes. Organometallics 25, 48-53 (2006).

18 Kai, H., Ohshita, J., Ohara, S., Nakayama, N., Kunai, A., Lee, I.-S. \& Kwak, Y.-W. Disilane- and siloxane-bridged biphenyl and bithiophene derivatives as electrontransporting materials in OLEDs. J. Organomet. Chem. 693, 3490-3494 (2008).

19 Ohshita, J., Nakashima, M., Tanaka, D., Morihara, Y., Fueno, H. \& Tanaka, K. Preparation of a D-A polymer with disilanobithiophene as a new donor component and application to high-voltage bulk heterojunction polymer solar cells. Polym. Chem. 5, 346-349 (2014)

20 Pei, J., Wen, S., Zhou, Y., Dong, Q., Liu, Z., Zhang, J. \& Tian, W. A low band gap donor acceptor copolymer containing fluorene and benzothiadiazole units: synthesis and photovoltaic properties. New J. Chem. 35, 385-393 (2011).

$21 \mathrm{Du}, \mathrm{C} ., \mathrm{Li}, \mathrm{W} ., \mathrm{Li}, \mathrm{C}$. \& Bo, Z. Ethynylene-containing donor-acceptor alternating conjugated polymers: Synthesis and photovoltaic properties. J. Polym. Sci. A Polym. Chem. 51, 383-393 (2013).

22 Piliego, C., Holcombe, W. T., Douglas, D. J., Woo, H. C., Beaujuge, M. P. \& Fre'chet, J. M. J. Synthetic control of structural order in N-Alkylthieno[3,4-c]pyrrole-4,6-dionebased polymers for efficient solar cells. J. Am. Chem. Soc. 132, 7595-7597 (2010).

23 Ohshita, J., Miyazaki, M., Zhang, F.-B., Tanaka, D. \& Morihara, Y. Synthesis and properties of dithienometallole-pyridinochalcogenadiazole alternate polymers. Polym. J. 45, 979-984 (2013).

24 Yue, S., Berry, C. G. \& McCullough, D. R. Intermolecular association and supramolecular organization in dilute solution. 1. Regioregular Poly(3-dodecylthiophene). Macromolecules 29, 933-939 (1996).

25 Zhou, C.-Z., Liu, T., Lin, T.-T., Zhan, X.-H. \& Chen, Z.-K. Morphology and photophysical properties of phenyleneethynylene oligomer. Polymer 46, 10952-10959 (2005)

26 Clark, J., Silva, C., Friend, H. R. \& Spano, C. F. Role of intermolecular coupling in the photophysics of disordered organic semiconductors: aggregate emission in regioregular polythiophene. Phys. Rev. Lett. 98, 206406 (2007).

27 Turner, T. S., Pingel, P., Steyrleuthner, R., Crossland, J. W. E., Ludwigs, S. \& Neher, D. Quantitative analysis of bulk heterojunction films using linear absorption spectroscopy and solar cell performance. Adv. Funct. Mater. 21, 4640-4652 (2011).

Supplementary Information accompanies the paper on Polymer Journal website (http://www.nature.com/pj) 